\title{
Assessing the Solar Power Plant Efficiency Degradation Resulting from Heating
}

\author{
Alexander Lavrik ${ }^{1}$ Emilia Yakovleva ${ }^{2 *}$, Alexander Leskov ${ }^{1}$ \\ 1 Department of Electric Power Engineering and Electromechanics, Saint-Petersburg Mining University, 2, \\ 21-st Line, Vasilyevsky Island, 199106, St. Petersburg, Russian Federation \\ 2 Department of General Electrical Engineering, Saint-Petersburg Mining University, 2, 21-st Line, Vasilyevsky \\ Island, 199106, St. Petersburg, Russian Federation \\ * Corresponding author's e-mail: em88mi@gmail.com
}

\begin{abstract}
Renewable power sources (RPS) play an ever growing role in power production. With the green power cost decreasing, the RPS share (including hydro power plants) in power production grows fast. Using RPS in supplying power to various facilities reduces the $\mathrm{CO}_{2}$ emission into atmosphere, thus reducing the greenhouse effect and being a fundamental factor in fighting the global warming. Every type of RPS possesses certain drawbacks that need to be eliminated. RPS units do have disadvantages, too, including low efficiency coefficient, and low specific power. However, there is the need for specific technological conditions. The present work describes the issue of photoelectric module heating. Photoelectric module heating results in both lower output voltage and module aging acceleration. The present work offers the method for assessing the practicability of development and implementation of solar power cell module active cooling systems, based on the photoelectric module daily performance schedules, drawing on statistic meteorological data collected over many years, and also it presents the brief description of various methods for cooling photoelectric modules.
\end{abstract}

Keywords: photoelectric module, PEM, solar power plant, performance coefficient, heating, cooling.

\section{INTRODUCTION}

Solar radiation potential in power production is one of the most significant alternative power generation sources. The maximum radiation flux at the sea level near equator may be $1020 \mathrm{~W} /$ $\mathrm{m}^{2}$. At medium latitude, the same value may be around $800 \mathrm{~W} / \mathrm{m}^{2}$ during summer and $300 \mathrm{~W} /$ $\mathrm{m}^{2}$ during winter. Despite the potential being so noticeable, the usage of the solar power is still limited, with minimum $80 \%$ of the solar radiation being reflected from the solar cell surface or transformed into heat (Chow 2010). Heating a solar cell adversely affects its performance. For crystalline silicon elements, the relative reduction of the efficiency coefficient may be $0.45 \%$ for every degree Celsius (Skoplaki and Palyvos 2009). In addition, a research was performed to prove the negative influence by higher temperatures on the system's lifespan. It was revealed that gaining every extra $10^{\circ} \mathrm{C}$ accelerates the aging process approximately twice (Otth and Ross 1983).

\section{STUDY AREA}

One direction of the research on improving the PEM efficiency includes the module cooling systems. Multiple options for cooling the solar modules are available today. The cooling methods may be divided into the passive methods and active ones.

The passive methods of cooling may include installation of aluminum or copper radiators on the back side of a module (Belskiy and Dobush 2006). Besides, recently it has become a common practice to apply thin layers of various materials to the silicon crystals. The key feature of those 
methods is that such layers are transparent for the visible and UV parts of the spectrum used by a solar cell, at the same time being capable of emitting or reflecting the infrared light. Certain researches (Nilsson et al. 1992) aim to achieve the balance temperature of the solar cell module below the ambient air temperature. It comes with a larger part of the solar power being reflected instead of being turned onto heat: for example, cooling a solar cell during daytime down below the ambient temperature needs more than $88 \%$ of the solar radiation to be bounced back. For example, the work (Zhu and Raman 2014) discloses the data on studying the efficiency of various silicon dioxide coating application methods. Figure 1 presents the comparison pertaining to the structure of the photoelectric module samples

According to the results of the research, applying the pyramid configuration of silicon dioxide emitting layer allows dropping $18^{\circ} \mathrm{C}$ with the insolation power of $800 \mathrm{~W} / \mathrm{m}^{2}$.

It is worth mentioning that the samples with the pyramid silicon dioxide layer applied thereon may only be obtained in a laboratory. Applying the even layer of the emitting silicon, too, is not an industrial option due to enormous cost thereof. Yet, this particular direction in connection with passive cooling methods remains one of the most promising.

Improving the active methods of solar power cell modules has certain issues, resulting mainly from the noticeable mismatch between the effect obtained and the power losses in connection with the implementation thereof. Such methods include various methods involving cooling fluid or air forced circulation by the channels or the surface of panels. For example, researchers used to propose cooling with a thin film of water flowing on the face surface of a module (Krauter 2004, Dorobantu and Popescu 2013), spraying water over the surface of modules (Hosseini et al. 2011), as well as submerging the modules into distilled water at various depths (Abdulgafar et al 2014). It is worth mentioning that the abovementioned works presented the effect without the power losses necessary for obtaining it taken into account.

In addition to the above-mentioned methods, there are works disclosing the hybrid cogeneration allowing obtaining electricity and hot water. Experimental samples of such combined systems are already tested at various facilities, and the photoelectric module efficiency coefficient improvement approaches 15\% (Jouhara, Milko and Danielewicz 2016).

Searching for optimal ways to cool down the photoelectric modules will, in the near future, necessitate the task to assess the practicability of implementing one or another cooling system at each particular facility. The assessment like this would be more rational, if it was performed by calculating the solar power plant efficiency co-

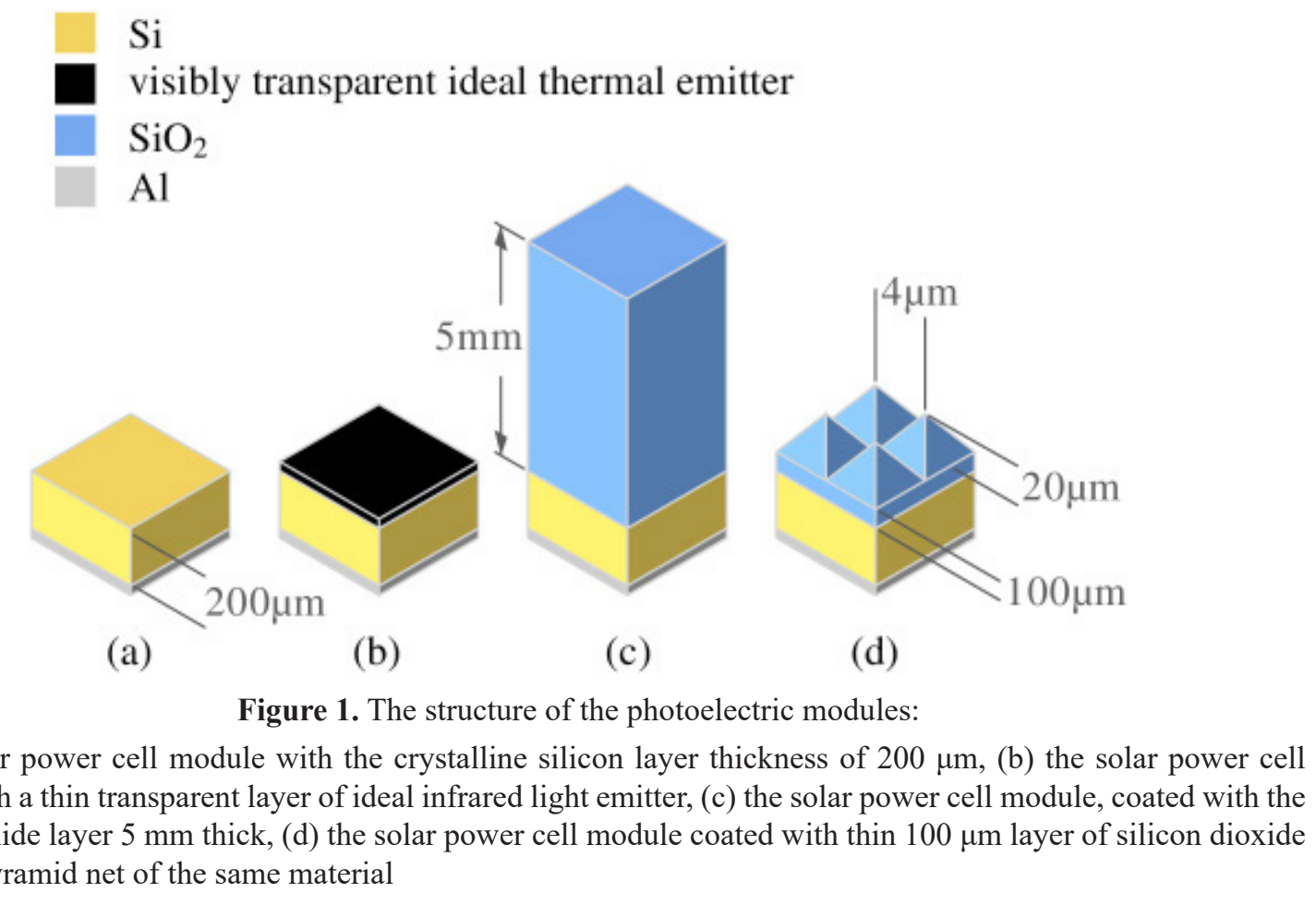


efficient, based on the statistical meteorological data collected over many years for the chosen geographic location.

A number of works paid attention to the correlation between the module temperature and performance. According to (Skoplaki and Palyvos 2009), the efficiency coefficient of a photoelectric module may be

$$
\eta_{c}=\eta_{T r e f} \cdot\left(1-\beta_{r e f} \cdot\left(T_{c}-T_{r e f}\right)\right)
$$

where: $\eta_{\tilde{n}}$ is the efficiency coefficient of a photoelectric module;

$\eta_{\dot{O}_{\text {ref }}}$ is the module efficiency coefficient at normal temperature;

$\beta_{\text {ref }}$ is the temperature coefficient, $\left[{ }^{\circ} \mathrm{C}^{-1}\right]$;

$T_{c}$ is the module temperature $\left[{ }^{\circ} \mathrm{C}\right]$,

$T_{\text {ref }}$ is the normal ambient temperature $\left[{ }^{\circ} \mathrm{C}\right]$.

The normal ambient air temperature is usually $25^{\circ} \mathrm{C}$, and the photoelectric module efficiency coefficient $\eta_{\dot{\partial} \text { ref }}$ with the coefficient $\beta_{\text {ref }}$ in the specifications are given for this normal temperature. The temperature coefficient of the module would be calculated in accordance with the expression

$$
\beta_{\text {ref }}=\frac{1}{T_{0}-T_{r e f}},
$$

where: $T_{0}$ is the critical temperature, under which the module efficiency coefficient approaches zero.

For silicon elements, $T_{0} \approx 270{ }^{\circ} \tilde{N}$, and for crystalline silicon modules $\beta_{\text {ref }} \approx 0.0041{ }^{\circ} \tilde{N}^{-1}$.

The solar cell module temperature may be calculated as [11]

$$
T_{c}=T_{a}+\frac{N O C T-20}{80} G,
$$

where: $T_{\grave{a}}$ is the ambient temperature $\left[{ }^{\circ} \mathrm{C}\right]$, NOCT is the nominal operating temperature of the element, $\left[{ }^{\circ} \mathrm{C}\right]$,

$G$ is the solar radiation power $\left[\mathrm{mW} / \mathrm{cm}^{2}\right]$.

The nominal operating cell temperature (NOCT) is the temperature of a photoelectric element at solar radiation power $800 \mathrm{~W} / \mathrm{m}^{2}$, ambient air temperature $20^{\circ} \mathrm{C}$, wind speed $1 \mathrm{~m} / \mathrm{s}$ and with the back surface of the panel exposed. Most silicon panels have NOCT around $48^{\circ} \mathrm{C}$.
Putting (3) into (1) gives

$\eta_{c}=\eta_{T \text { ref }} \cdot\left(1-\beta_{r e f} \cdot\left(T_{a}+\frac{N O C T-20}{80} G-T_{r e f}\right)\right)$

Therefore, calculation of the actual photoelectric panel efficiency coefficient requires, in addition to specification data, the information about the air temperature and the solar radiation value. Because a day is the production cycle of a solar power plant production, the cooling system efficiency assessment would preferably be performed based on the efficiency coefficient daily schedule. Then, the meteorological data should comprise the daily temperature and solar radiation shift data for the chosen geographic location.

\section{RESULTS}

The actual efficiency coefficient for a $100 \mathrm{~kW}$ solar power plant by the "AltEnergo" company located in the city of Belgorod was calculated as an example. The solar power plant combined with wind power generators, acts as proving grounds for the scientific studies performed by the company.

The PEMs in the Belgorod power plant are of polycrystalline type with the efficiency coefficient $15.5 \%$. The position of the Sun is not followed.

Figure 2 shows the daily shift in solar radiation and the ambient air temperature in the city of Belgorod for July, with the data being averaged for all days of July between 1997 and 2017.

With the expression (4), and with the solar power plant PEM specification data, one can build the PEM temperature and efficiency coefficient diagrams during the day.

The nominal polycrystalline photoelectric module efficiency coefficient for PEMs installed at the power plant equals $15.5 \%$. When heated above $25^{\circ} \mathrm{C}$, a degradation of the efficiency coefficient occurs. Expressed absolutely, the efficiency degradation was $1.9 \%$. The maximum relative efficiency coefficient degradation was $12 \%$ : $\eta_{c} / \eta_{\text {ref }}=0.88$.

The analysis of the diagrams in the figures 2 and 3 showed that the main contribution into PEM heating comes from the solar radiation. The ambient air temperature approaches maximum after 15:00 hours, moving the maximum heating point to the right, towards 14:00 hours. The theoretical power production $E$ of the power plant would be 


$$
E=G \cdot \eta_{c}=4593 \kappa B m \cdot \varphi
$$

while the power production $E_{\text {ref }}$ at operation with the nominal efficiency coefficient would be

$$
E_{\text {ref }}=G \cdot \eta_{\text {Tref }}=5037 \kappa B m \cdot \varphi \text {. }
$$

Then, the average losses $\Delta E_{m}$ resulting from heating the PEMs in July would be

$$
\begin{gathered}
\Delta E_{m}=\left(E_{r e f}-E\right) \cdot n=1 \\
=(5037-4593) \cdot 31=13764 \kappa \mathrm{Bm} \cdot \varphi
\end{gathered}
$$

It is worth mentioning even stronger heating at the southern regions of the country with higher average air temperature and insolation constitutes a more significant actual issue with the PEM efficiency.

\section{CONCLUSIONS}

The PEM efficiency coefficient and electric power losses calculation should be performed based on the statistical meteorological data for the power plant location always before making one's decision on the practicability of cooling system design or implementation. The fact that such systems operate only for part of a day, when solar panel efficiency coefficient losses are at maximum should be taken into account. Depending on power losses on cooling, particular operating hours should be selected for such a system. That is why building module efficiency coefficient diagrams during the day may be particularly useful when active cooling systems are designed.

Improved PEM performance expands the module usability, reducing emissions into the

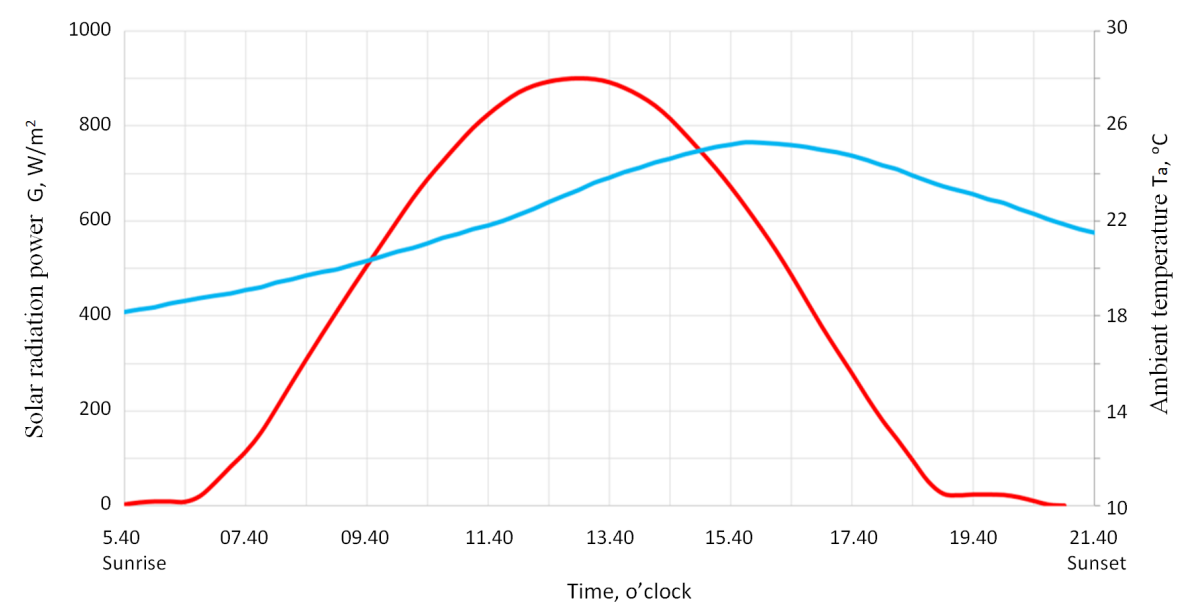

Figure 2. Changing solar radiation power at the panel surface (red curve) and changing ambient temperature (blue curve) during a day

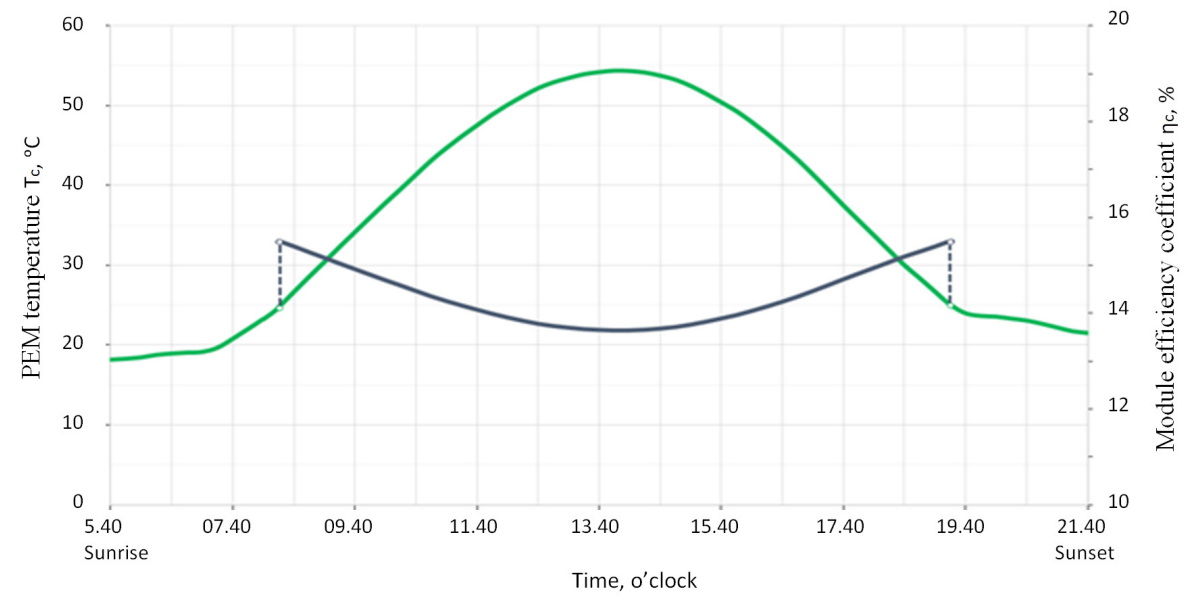

Figure 3. Changes in the PEM temperature (green curve) and module efficiency coefficient (black curve) during the day 
atmosphere. Besides, longer lifespan of PEMs also contributes into reducing the negative environmental effects during solar cell production. This indicates the relevance of the solar cell performance improvement issue, and in particular, refers to designing the PEM cooling system for photovoltaics as an important component of the planet's ecological safety.

\section{REFERENCES}

1. Abdulgafar S.A., Omar O.S., Yousif K.M. 2014. Improving the efficiency of polycrystalline solar panel via water immersion method. International Journal of Innovative Research in Science, Engineering and Technology, 3(1), 96-101.

2. Belskiy A.A., Dobush V.S. 2006. Autonomous Electrothermal Facility for Oil Recovery Intensification Fed by Wind Driven Power Unit. IOP Conference Series: Earth and Environmental Science, 87(3), 56-60.

3. Chow T.T. 2010. A review on photovoltaic/thermal hybrid solar technology. Applied Energy, 87, 365-379.

4. Dorobantu L., Popescu M.O. 2013. Increasing the Efficiency of Photovoltaic Panels Through Cooling Water Film. U.P.B. Sci. Bull, Series C, 75(4), 223-230.
5. Hosseini R., Hosseini N., Khorasanizadeh H. 2011. An experimental study of combining a photovoltaic system with a heating system, World Renewable Energy Congress, 8, 2993-3000.

6. Jouhara H., Milko J., Danielewicz J. 2016. The performance of a novel flat heat pipe based thermal and PV/T solar collector that can be used as an energy-active building envelope material. Energy, 108, 148-154.

7. Krauter S. 2004. Increased electrical yield via water flow over the front of photovoltaic panels. Solar Energy Materials and Solar Cells, 82(1-2), 131-137.

8. Nilsson T.M., Niklasson G.A., Granqvist C.G. 1992. A solar reflecting material for radiative cooling applications: ZnS pigmented polyethylene. Solar Energy Materials and Solar Cells, 28, 175-193.

9. Otth D., Ross Jr.R.E. 1983. Assessing photovoltaic module degradation and lifetime from long term environmental tests. Proceedings of the Institute of Environmental Sciences, 29th Annual Meeting, 121-126.

10. Ross R.G. 1980. Flate-plate photovoltaic array design optimization. 14th IEEE Photovoltaic Specialists Conference, 1126-1132.

11. Skoplaki E., Palyvos J. 2009. On the temperature dependence of photovoltaic module electrical performance: a review of efficiency/power correlations. Sol. Energy, 83, 614-624.

12. Zhu L., Raman A. 2014. Radiative cooling of solar cells. Optica, 1(1), 32-38. 